\title{
Brief interventions for alcohol and other drug use
}

\section{SUMMARY}

Brief interventions essentially include screening and assessment of all patients about their alcohol or other drug use. This then allows the clinician to provide information and advice to reduce the harms associated with risky use.

These interventions are generally opportunistic and are offered to people who have not sought assistance but have been identified through routine screening.

Brief interventions are more effective in people who are 'at risk' of developing dependence rather than those who are already dependent or experiencing severe drug-related harms.

The effectiveness of brief interventions in the real-world setting has been questioned in recent years.

Brief interventions should be repeated whenever possible rather than focusing on a single session.

\section{Craig Rodgers}

Senior staff specialist, Alcohol and Drug Service, St Vincent's Hospital, Sydney

\section{Keywords}

alcohol use, binge drinking, brief intervention, drug dependence

Aust Prescr 2018;41:117-21 https://doi.org/10.18773/ austprescr.2018.031

\section{Introduction}

' 5 minutes is as good as 20 ' is what we often say when we discuss brief interventions for alcohol and drug misuse. But what exactly are brief interventions and are they really effective?

Alcohol and other drug use is of particular concern in Australia. The 2016 National Drug Strategy Household survey revealed that $17 \%$ of Australians aged 12 years or older drank harmful levels of alcohol.' This equates to drinking more than two standard drinks ( $10 \mathrm{~g}$ of alcohol) per day. In addition, 36\% had consumed five or more standard drinks on a single occasion at least once in the past year. This exceeds the National Health and Medical Research Council single occasion risk guidelines. ${ }^{2}$

We know that alcohol carries a significant burden of disease costing the Australian economy at least $\$ 15$ billion. ${ }^{3,4}$ The cost of illicit drug use is also high at approximately $\$ 8$ billion per year. ${ }^{3}$

\section{History}

Brief interventions can be traced back to work done in the early 1960s in Boston and London at roughly the same time. ${ }^{5}$ The Boston intervention involved a psychiatrist and a social worker seeking to capitalise on the emergency care visit by referring the patient to out-patient alcohol treatment. The intervention involved 'meeting patients initially with understanding, sympathy and attention to expressed needs, however concrete they may be'. The London study is widely credited as being a seminal influence on ending abstinence as the exclusive goal of alcohol treatment and recognising controlled drinking as being an acceptable outcome. ${ }^{5}$

Further work in 2003 saw the development of the Screening, Brief Intervention, and Referral to Treatment (SBIRT) tool. This was developed in the USA for healthcare settings to address the full spectrum of unhealthy alcohol and drug use, including those with more severe alcohol-related conditions. ${ }^{6}$

\section{What are brief interventions?}

The World Health Organization (WHO) defines brief interventions as 'practices that aim to identify a real or potential alcohol (or other drug) problem and motivate an individual to do something about it.'. They include screening and assessment, which then allows the clinician to provide information and advice to reduce risky alcohol or other drug consumption and related problems. ${ }^{7}$ They are generally opportunistic and are offered to people who have not sought treatment or assistance but have been identified through routine screening.?

Brief interventions aim to inform people that they are drinking or using drugs at levels that increase their risk of developing abuse or dependence disorders and to encourage them to decrease consumption to reduce risk. ${ }^{7}$ They are not usually effective in people who have developed dependence or who are experiencing severe drug-related harms. More intensive treatment interventions by drug and alcohol specialist services are recommended for these people? 


\section{How and when are brief interventions conducted?}

While brief interventions have largely focused on primary care settings, any healthcare professional with adequate training can conduct them. Practice nurses in particular may be more suited due to the time constraints of GPs and may be more cost effective. ${ }^{8}$

Using computers to deliver screening tools has also been touted as more viable than pen-and-paper questionnaires. ${ }^{8}$ The internet and mobile devices provide new possibilities for standalone or facilitated interventions, ${ }^{9}$ and would also offer benefits such as greater validity and anonymity.

When to undertake brief interventions is also an area of confusion. They can readily be performed in the following scenarios: ${ }^{10}$

- all new patients

- health assessments

- chronic disease assessments, for example hypertension, diabetes, gastro-oesophageal reflux disease, abnormal liver function tests.

Repeating brief interventions whenever possible rather than focusing on a single session, has been argued to improve efficacy. ${ }^{6,1}$

Just as brief interventions originated in the emergency department, this should also be a logical place to deliver them. However, more recent research has shown that even with 'booster sessions' by telephone after an emergency department visit, brief interventions did not improve outcomes at 12 months. $^{12}$

\section{Do brief interventions work?}

Many trials and meta-analyses indicate that brief interventions are efficacious as secondary prevention strategies, particularly when targeting alcohol consumption. A meta-analysis in 1997 found that heavy drinkers were twice as likely to have lowered their consumption 6-12 months after a brief intervention than those who received no intervention. ${ }^{13}$ Similarly, a WHO study conducted in eight countries (>1600 participants) found that brief interventions reduced daily alcohol consumption by $17 \%$ and intensity of drinking by $10 \% .^{14}$

Brief interventions were also hailed as reducing alcohol-related problems, healthcare use and treatment costs, and the number of emergency department admissions. ${ }^{8}$ A meta-analysis in 2007 of 22 trials identified an overall reduction in drinking of almost four Australian standard drinks (38 g) per week at one year.15 An updated meta-analysis now including 34 studies in 2018 still showed evidence of a reduction in drinking one year after a brief intervention but this had reduced to the equivalent of two Australian standard drinks (20 g). ${ }^{16}$

In more recent years the effectiveness of brief interventions in the real-world setting has been questioned. 6,9,10 While the 2007 meta-analysis was reassuring in some ways, there were clinically meaningful uncertainties including a major sex difference with men reducing their mean alcohol intake by six standard drinks whereas women only reduced their intake by one standard drink. ${ }^{10,15}$ The more recent review in 2018 now shows that both men and women reduce their drinking equally after receiving a brief intervention. ${ }^{16}$ It was also disputed that the 2007 review found that trials reporting the largest effects did not take place in primary care or were at high risk of bias. In addition, other large UK general practice trials of brief interventions for alcohol found no benefit. 17,18

\section{Practical resources to support brief interventions}

A critical barrier to implementing brief interventions is the failure to screen and detect individuals at risk of developing alcohol and other drug problems. ${ }^{8}$ In general practice, this has been linked to limited access to resources, lack of time, heavy workloads, lack of confidence and concerns about raising sensitive or private issues. Some GPs simply feel that responding to alcohol and other drug issues is not a legitimate part of their work. ${ }^{4,8}$

There are several frameworks now in place to guide clinicians on appropriate screening or assessment. One of the earlier frameworks is summarised as 'FLAGS' - Feedback, Listen, Advice, Goals, Strategies (Table 1). An alternative acronym such as 'FRAMES' (Feedback, Responsibility, Advice, Menu of options, Empathy, Self-Efficacy) may also be used.?

A more recent framework supported by the Royal Australian College of General Practitioners is the ' $5 \mathrm{As}$ ' Ask, Assess, Advise/Agree, Assist, Arrange (Table 2). ${ }^{19}$ While these frameworks are useful to guide clinicians on how to structure brief interventions, they still need other tools when trying to assess if alcohol or other drug use is causing harm.

A simple but useful tool for engaging patients in discussion about their alcohol use is the AUDIT-C, which is a modification of the Alcohol Use Disorders Identification Test $^{10}$ (Table 3). While it might seem impersonal to be using tools such as these, the assessment process itself may be the 'active ingredient' of brief interventions and may explain why longer interventions are no better than shorter ones. ${ }^{10}$ The AUDIT-C is a useful tool for assessing alcohol use, however it may be more difficult to assess for other 


\section{Table 1 FLAGS brief intervention tool for alcohol problems}

\begin{tabular}{|c|c|}
\hline \multirow[t]{2}{*}{ Feedback } & $\begin{array}{l}\text { Provide individualised feedback about the risks associated with continued drinking, based on current } \\
\text { drinking patterns, problem indicators and health status. }\end{array}$ \\
\hline & Discuss the potential health problems that can arise from risky alcohol use. \\
\hline \multirow[t]{2}{*}{ Listen } & Listen to the patient's response. \\
\hline & $\begin{array}{l}\text { This should spark a discussion of the patient's consumption and how it relates to the general population } \\
\text { consumption and any false beliefs held by the patient. }\end{array}$ \\
\hline \multirow[t]{3}{*}{ Advice } & $\begin{array}{l}\text { Give clear advice about the importance of changing current drinking patterns and a recommended level } \\
\text { of consumption. }\end{array}$ \\
\hline & $\begin{array}{l}\text { A typical 5-10 minute brief intervention should involve advice on reducing consumption in a persuasive but } \\
\text { non-judgmental way. }\end{array}$ \\
\hline & $\begin{array}{l}\text { Advice can be supported by self-help materials that provide information about the potential harms of risky } \\
\text { alcohol consumption and can provide additional motivation to change. }\end{array}$ \\
\hline \multirow[t]{3}{*}{ Goals } & $\begin{array}{l}\text { Discuss the safe drinking limits and assist the patient to set specific goals for changing patterns } \\
\text { of consumption. }\end{array}$ \\
\hline & Instil the optimism in the patient that his or her chosen goals can be achieved. \\
\hline & $\begin{array}{l}\text { It is in this step, in particular, that motivation-enhancing techniques are used to encourage patients to } \\
\text { develop, implement and commit to plans to stop drinking. }\end{array}$ \\
\hline \multirow[t]{3}{*}{ Strategies } & Ask the patient to suggest some strategies for achieving these goals. \\
\hline & $\begin{array}{l}\text { This approach emphasises the individual's choice to reduce drinking patterns and allows them to choose the } \\
\text { approach best suited to their own situation. }\end{array}$ \\
\hline & $\begin{array}{l}\text { The individual might consider setting a specific limit on alcohol consumption, learning to recognise the } \\
\text { antecedents of drinking, and developing skills to avoid drinking in high-risk situations, pacing one's drinking } \\
\text { and learning to cope with everyday problems that lead to drinking. }\end{array}$ \\
\hline
\end{tabular}

Source: reference 7

drug use and this may be due to the clinician's lack of knowledge of certain drugs. Useful sources about other drugs include:

- Your Room - a place to get facts about alcohol or other drugs https://yourroom.health.nsw.gov.au/ Pages/home.aspx

- Alcohol and Drug Foundation https://adf.org.au/ drug-facts.

There are also more nuanced tools to guide the assessment process such as the Severity of Dependence Scale (SDS) ${ }^{20}$ (Box 1), or more recently the Alcohol, Smoking and Substance Involvement Screening Test (ASSIST-Lite). ${ }^{21}$ The SDS was devised to provide a short, easily administered scale to measure the degree of dependence to different types of drugs. The SDS contains five items, all of which are explicitly concerned with psychological components of dependence, including impaired control over drug taking and preoccupation and anxieties about drug use. The SDS score is related to behavioural patterns of drug taking that are, in themselves, indicators of dependence, such as dose, frequency of use, duration of use, daily use and degree of contact with other drug users. It also shows validity in that drug users

\section{Table 2 The 5As framework for preventive care}

\begin{tabular}{ll} 
Ask & Identify patients with risk factors \\
Assess & Level of risk factor and its relevance to the individual in terms of health \\
& Readiness to change \\
& Health literacy \\
Advise/Agree & Provide written information \\
& $\begin{array}{l}\text { Brief advice and motivational interviewing } \\
\text { Negotiate goals and targets (including a lifestyle prescription) }\end{array}$ \\
Assist & $\begin{array}{l}\text { Develop a risk factor management plan that may include lifestyle } \\
\text { education tailored to the individual (e.g. based on severity of risk } \\
\text { factors, comorbidities) and pharmacotherapies } \\
\text { Support for self-monitoring } \\
\text { Arrange }\end{array}$ \\
\hline
\end{tabular}

Reproduced with permission from The Royal Australian College of General Practitioners from Smoking, nutrition, alcohol, physical activity (SNAP): a population health guide to behavioural risk factors in general practice, 2nd ed. Melbourne: The Royal Australian College of General Practitioners; 2015. p. 6-7. Available at www.racgp.org.au/yourpractice/guidelines/snap ${ }^{19}$ 
Table 3 AUDIT-C questionnaire for engaging patients about their alcohol use

\begin{tabular}{lc}
\hline Questions & Score \\
\hline How often do you have a drink containing alcohol? & \\
Never & +0 \\
Monthly or less & +1 \\
$2-4$ times per month & +2 \\
2 -3 times per week & +3 \\
4 or more times a week & +4 \\
How many standard drinks containing alcohol do you have on a typical day? & \\
1 or 2 & +0 \\
3 or 4 & +1 \\
5 or 6 & +2 \\
7 or 9 & +3 \\
10 or more & +4 \\
\hline How often do you have six or more drinks on one occasion? & \\
Never & +0 \\
Less than monthly & +1 \\
Monthly & +2 \\
Weekly & +3 \\
\hline Daily or almost daily & +3 \\
\hline
\end{tabular}

Risky drinker: Male - AUDIT-C $\geq 5$ Female - AUDIT-C $\geq 4$

Reproduced with permission from The Royal Australian College of General Practitioners from Tam CW, Knight A, Liaw ST. Alcohol screening and brief interventions in primary care: evidence and a pragmatic practice-based approach. Aust Fam Physician 2016;45:767-70. Available at www.racgp.org.au/afp/2016/october/ alcohol-screening-and-brief-interventions-in-primary-care-evidence-and-a-pragmaticpractice-based-approachio

\section{Box 1 Severity of Dependence Scale for assessing the degree of drug and alcohol dependence}

In the past month...

Have you ever thought your [named drug] use was out of control?

Never (0) Sometimes (1) Often (2) Always (3)

Has the thought of not being able to get any [named drug] really stressed you at all?

Never (0) Sometimes (1) Often (2) Always (3)

Have you worried about your [named drug] use?

Never (0) Sometimes (1) Often (2) Always (3)

Have you wished that you could stop?

Never (0) Sometimes (1) Often (2) Always (3)

How difficult would you find it to stop or go without?

Not difficult (0) Quite difficult (1) Very difficult (2) Impossible (3)

Score $\geq 4$ is positive for substance dependence

Source: adapted from reference 20 who have sought treatment at specialist and nonspecialist services for drug problems have higher SDS scores than non-treatment samples. Essentially higher total scores indicate higher levels of dependence, although it is recognised that a score of 4 or more is positive for substance dependence. ${ }^{20}$

The ASSIST-Lite tool may be suitable for primary care scenarios, in particular for drugs such as amphetamines, as it was designed to be an ultrarapid screening tool for substance use disorders. ${ }^{21}$ It generally assesses drug use over the last three months and covers a range of substances. Box 2 highlights its use for amphetamines.

\section{Conclusion}

While recent evidence suggests there may be reason to question whether brief interventions work in routine clinical practice, in some individuals they will certainly make a difference. ${ }^{10} \mathrm{~A}$ pragmatic approach would be to ensure that all patients are asked about drug and alcohol use in the first instance. This then allows for further assessments to determine current harms. Advice can be given if their use is harmful and goals for change can be established. This should be repeated at every chance you can. At the very least, it may help start a conversation with someone who may then reflect on their behaviour and consider making some positive changes in their life. $\varangle$

Conflict of interest: none declared

\section{Box 2 ASSIST-Lite tool for assessing recent drug use (stimulants)}

In the past 3 months...

1. Did you use an amphetamine-type stimulant, or cocaine, or a stimulant medication not as prescribed? Yes (1) No (0)

If YES

2. Did you use a stimulant at least once each week or more often?

Yes (1) No (0)

3. Has anyone expressed concern about your use of a stimulant?

Yes (1) No (0)

Score $\geq 2$ is positive for substance dependence.

Source: adapted with permission from reference 21 


\section{REFERENCES}

1. Australian Institute of Health and Welfare. National Drug Strategy Household Survey 2016: detailed findings. Drug Statistics series no. 31. Cat. no. PHE 214. Canberra: AlHW 2017. https://www.aihw.gov.au/reports/illicit-use-ofdrugs/2016-ndshs-detailed/contents/table-of-contents [cited $2018 \mathrm{Jul} 1]$

2. National Health and Medical Research Council. Australian guidelines to reduce health risks from drinking alcohol. Canberra: Commonwealth of Australia; 2009. https://www.nhmrc.gov.au/guidelines-publications/ds10 [cited $2018 \mathrm{Jul} 1$ ]

3. Collins DJ, Lapsley HM. The costs of tobacco, alcohol and illicit drug abuse to Australian society in 2004/05. Canberra: Commonwealth of Australia; 2008. http://www.health.gov.au/ internet/drugstrategy/publishing.nsf/content/mono64 [cited 2018 Jul 1]

4. Pennay A, Lubman DI, Frei M. Alcohol: prevention, policy and primary care responses. Aust Fam Physician 2014;43:356-61.

5. McCambridge J, Cunningham JA. The early history of ideas on brief interventions for alcohol. Addiction 2014;109:538-46. https://doi.org/10.1111/add.12458

6. Glass JE, Andréasson S, Bradley KA, Finn SW, Williams EC, Bakshi A-S, et al. Rethinking alcohol interventions in health care: a thematic meeting of the International Network on Brief Interventions for Alcohol \& Other Drugs (INEBRIA) Addict Sci Clin Pract 2017;12:14. https://doi.org/10.1186/ s13722-017-0079-8

7. Haber P, Lintzeris N, Proude E, Lopatko O. Guidelines for the treatment of alcohol problems. Canberra: Commonwealth of Australia; 2009. http://www.alcohol.gov.au/internet/ alcohol/publishing.nsf/Content/guidelines-treat-alc-09 [cited $2018 \mathrm{Jul} 1]$

8. Roche AM, Freeman T. Brief interventions: good in theory but weak in practice. Drug Alcohol Rev 2004:23:11-8. https://doi.org/10.1080/09595230410001645510

9. McCambridge J, Saitz R. Rethinking brief interventions for alcohol in general practice. BMJ 2017;356:j116. https://doi.org/ 10.1136/bmj.j116

10. Tam CW, Knight A, Liaw ST. Alcohol screening and brief interventions in primary care: evidence and a pragmatic practice-based approach. Aust Fam Physician 2016;45:767-70.

11. Jonas DE, Garbutt JC, Amick HR, Brown JM, Brownley KA, Council $\mathrm{CL}$, et al. Behavioral counseling after screening for alcohol misuse in primary care: a systematic review and meta-analysis for the US Preventive Services Task Force. Ann Intern Med 2012;157:645-54. https://doi.org/10.7326/ 0003-4819-157-9-201211060-00544
12. Bogenschutz MP, Donovan DM, Mandler RN, Perl HI, Forcehimes AA, Crandall C, et al. Brief intervention for patients with problematic drug use presenting in emergency departments: a randomized clinical trial. JAMA Intern Med 2014;174:1736-45. https://doi.org/10.1001/ jamainternmed.2014.4052

13. Wilk Al, Jensen NM, Havighurst TC. Meta-analysis of randomized control trials addressing brief interventions in heavy alcohol drinkers. J Gen Intern Med 1997;12:274-83. https://doi.org/10.1007/s11606-006-5063-z

14. WHO Brief Intervention Study Group. A cross-national trial of brief interventions with heavy drinkers. Am J Public Health 1996;86:948-55. https://doi.org/10.2105/AJPH.86.7.948

15. Kaner EFS, Dickinson HO, Beyer FR, Campbell F, Schlesinger C, Heather N, et al. Effectiveness of brief alcohol interventions in primary care populations. Cochrane Database Syst Rev 2007:CD004148. https://doi.org/10.1002/14651858.CD004148.pub3

16. Kaner EFS, Beyer FR, Muirhead C, Campbell F, Pienaar ED, Bertholet N, et al. Effectiveness of brief alcohol interventions in primary care populations. Cochrane Database Syst Rev 2018:CD004148. https://doi.org/10.1002/14651858.CD004148.pub4

17. Butler CC, Simpson SA, Hood K, Cohen D, Pickles T, Spanou C, et al. Training practitioners to deliver opportunistic multiple behaviour change counselling in primary care: a cluster randomised trial. BMJ 2013;346:f1191. https://doi.org/10.1136/bmj.f1191

18. Kaner E, Bland M, Cassidy P, Coulton S, Dale V, Deluca P, et al. Effectiveness of screening and brief alcohol intervention in primary care (SIPS trial): pragmatic cluster randomised controlled trial. BMJ 2013;346:e8501. https://doi.org/10.1136/bmj.e8501

19. Smoking, nutrition, alcohol, physical activity (SNAP): a population health guide to behavioural risk factors in general practice. 2nd ed. Melbourne: Royal Australian College of General Practitioners; 2015. https://www.racgp.org.au/yourpractice/guidelines/snap [cited $2018 \mathrm{Jul} 1]$

20. Gossop M, Darke S, Griffiths P, Hando J, Powis B, Hall W, et al. The Severity of Dependence Scale (SDS): psychometric properties of the SDS in English and Australian samples of heroin, cocaine and amphetamine users. Addiction 1995;90:607-14. https://doi.org/10.1046/ j.1360-0443.1995.9056072.x

21. Ali R, Meena S, Eastwood B, Richards I, Marsden J. Ultrarapid screening for substance-use disorders: the Alcohol, Smoking and Substance Involvement Screening Test (ASSIST-Lite). Drug Alcohol Depend 2013;132:352-61. https://doi.org/10.1016/j.drugalcdep.2013.03.001

\section{FURTHER READING}

World Health Organization. Management of substance abuse. Screening and brief intervention for alcohol problems in primary health care. Geneva: WHO; 2003. http://www.who.int/ substance_abuse/activities/sbi/en [cited 2018 Jul 1]

Centers for Disease Control and Prevention. Planning and implementing screening and brief intervention for risky alcohol use: a step-by-step guide for primary care practices. Atlanta, Georgia: Centers for Disease Control and Prevention, National Center on Birth Defects and Developmental Disabilities; 2014 https://www.cdc.gov/ncbddd/fasd/alcohol-screening.html [cited 2018 Jul 1]
SAMHSA-HRSA Center for Integrated Health Solutions. SBIRT: Screening, Brief Intervention, and Referral to Treatment. https://www.integration.samhsa.gov/clinical-practice/sbirt [cited 2018 Jul 1] 